\title{
Research Paper: Periodontal Diseases and Dental Caries in Children With Cerebral Palsy
}

\author{
Hamid Dalvand $^{1^{*}}$ (D), Leila Dehghan ${ }^{1}$ (D), Hooshang Dadgar² (D, Saman Maroufizadeh ${ }^{3}$ (D), Sarvin Sarmadi ${ }^{4}$ (D) \\ 1. Department of Occupational Therapy, School of Rehabilitation, Tehran University of Medical Sciences, Tehran, Iran. \\ 2. Department of Speech Therapy, School of Rehabilitation, Tehran University of Medical Sciences, Tehran, Iran. \\ 3. Department of Biostatistics, School of Nursing and Midwifery, Guilan University of Medical Sciences, Rasht, Iran. \\ 4. Department of Orthodontics, School of Dentistry, Tehran University of Medical Sciences, Tehran, Iran.
}

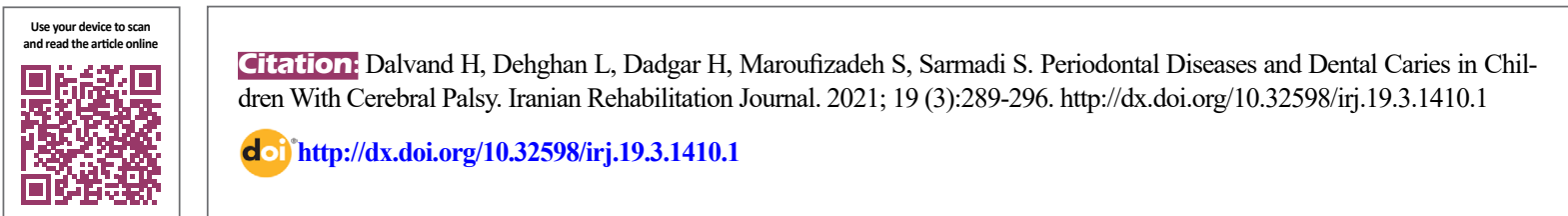

Article info:

Received: 27 Jun 2021

Accepted: 17 Aug 2021

Available Online: 01 Sep 2021

\section{Keywords:}

Cerebral palsy, Pediatrics, Periodontal disease, Decay, Missing, Filled tooth

\section{ABSTRACT}

Objectives: Musculoskeletal disorders in children with Cerebral Palsy (CP) affect the general health of the mouth and teeth. This study aimed to determine periodontal and dental diseases in children with $\mathrm{CP}$ based on gross motor function level, manual ability level, and subtypes of CP.

Methods: This research was a cross-sectional study performed on 123 children (3-18 years old) with CP referred to dentistry and rehabilitation centers supervised by Tehran University of Medical Sciences in 2019-2020. They were selected by the convenience sampling method. The children were classified according to the gross motor function classification system: expanded and revised (GMFCS-E\&R) for their gross motor function level, according to the manual ability function classification system (MACS) and mini-MACS for the functioning of their hands in handling objects, and according to the quality and topographical pattern of motor impairment for subtypes of $\mathrm{CP}$. The periodontal status of children with $\mathrm{CP}$ was evaluated according to the recommendation of the World Health Organization using the community periodontal index and for caries according to the decayed, missing, filled index. All statistical analyses were done by SPSS v. 16.

Results: The results showed significant differences between periodontal disease and sex, age, GMFCS-E\&R, MACS, mini-MACS levels, and subtypes of $\mathrm{CP}(\mathrm{P}<0.05)$. But there were no significant differences between teeth diseases and oral motor skills with sex, age, MACS and mini-MACS, GMFCS-E\&R levels, and subtypes of $\mathrm{CP}(\mathrm{P}>0.05)$.

Discussion: Periodontal disease and decayed, missing, filled teeth are common problems in CP children, and the conditions worsen with age and level IV and V of GMFCS-E\&R and MACS.

\section{* Corresponding Author:}

Hamid Dalvand, PhD.

Address: Department of Occupational Therapy, School of Rehabilitation, Tehran University of Medical Sciences, Tehran, Iran.

Tel: +98 (21) 77533939

E-mail: hdalvand@sina.tums.ac.ir 


\section{Highlights}

- In the present study, 68 children (55.3\%) with CP suffered from periodontitis.

- A significant relationship was found between periodontal disease and the subtype of CP.

- Periodontal diseases were higher in children aged 10-15 years and in levels IV, V GMFCS-E\&R in children with CP.

\section{Plain Language Summary}

Children with Cerebral Palsy (CP) are more at risk of poor oral health, that is negatively affects their quality of life. This matter may be due to the low ability to maintain hygiene, which, in turn, may make it difficult for CP children to feed. In this study, the community periodontal index and the decayed, missing, filled index were used to determine periodontal and dental diseases in children with $\mathrm{CP}$, based on gross motor function level, manual ability level, and subtypes of CP. In our study, $123 \mathrm{CP}$ children were selected by the convenience sampling method. The results showed periodontal disease and decayed, missing, filled teeth are common problems in CP children, and these situations get worse with age and level IV and V of GMFCS-E\&R (gross motor function classification system: expanded and revised) and MACS (manual ability function classification system).

\section{Introduction}

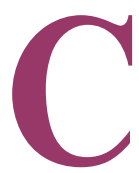

hildren with Cerebral Palsy (CP) usually have poor oral health due to neuromuscular problems [1]. More than $90 \%$ of CP children have motor-oral problems [2]. Neuromuscular problems in these children can cause changes in the structure of the mouth, gingiva, and teeth. These conditions cause nutritional problems, dental maintenance and hygiene status, and difficulty using dental care products [3]. Because of lack of motor coordination and reduction of their collaboration in effective oral care, children with $\mathrm{CP}$ are more at risk of tooth decay, which negatively affects their quality of life $[4,5]$. Studies have shown that gingival and periodontal diseases are more common in children with CP. This effect may be due to the low ability to maintain hygiene and the formation of biofilms [6]. Another critical issue is the use of anticonvulsant medicines, especially phenytoin [7]. Jan et al. (2016), in a review study of the oral health of children with $\mathrm{CP}$, reported that gingivitis and bleeding gums occur more frequently in children with $\mathrm{CP}$.

Difficulty in maintaining daily oral hygiene, intraoral hypersensitivity, and oral-facial dysfunction are the main causes of periodontal problems in these patients. Gingival hyperplasia is a predictor of periodontal disease and occurs more in children with spastic quadriplegia, especially in older ages [8]. Dos Santos et al. reported a higher prevalence of tooth decay in children with $\mathrm{CP}$ than in other diseases [9]. In another study, oral health-related quality of life decreased with increasing gross motor function, which seems to highlight the role of gross motor function in oral health in children with $\mathrm{CP}$ [10].

Lack of access to dental care leads to caries remaining untreated in these children and causing more problems. Mouth breathing, more oral infections, and food retention in the oral cavity (especially in the interdental space) can cause more caries in children with CP [11].

The oral health problems, in turn, may make it difficult for $\mathrm{CP}$ children to feed. On the other hand, the development of children with CP usually is slower than other children, and nutritional problems reduce the storage of fat and energy sources in these children and slow down the children's growth [12]. Considering the critical role of oral health management in feeding a child with $\mathrm{CP}$ and its effect on nutritional care, nutritional health, and decreasing oral health risk behaviors, this study aimed to determine periodontal and dental diseases in children with $\mathrm{CP}$ based on gross motor function, manual ability levels, and subtypes of CP.

\section{Materials and Methods}

\section{Study participants}

In this cross-sectional study, the statistical population consisted of all children with $\mathrm{CP}$ aged 3-18 years referred to dentistry and rehabilitation centers supervised by the Tehran University of Medical Sciences (TUMS) in 2019-2020. 
The sample size was estimated as 111 people taking into account the effect size of 0.3 , the type I error of 0.05 , and the test power of 0.8 according to the previous research and the researcher's expectations. Because of the probability of dropout, the sample size was considered 125 . Finally, $123 \mathrm{CP}$ children were selected by the convenience sampling method. Children who met the following inclusion criteria were included in the study: children with $\mathrm{CP}$ aged 3-18 diagnosed by a pediatric neurologist and free of vision and hearing problems, abnormalities of the oral structure, including cleft lip and palate; not under systemic antibiotics use in the last 3 months; and not received professional periodontal treatment in the last 3 months or dental services in the last 6 months. Children were excluded if they or their parents were not willing to participate in each study stage. This study protocol was approved by the Ethics Committee of TUMS (Code: IR.TUMS.FNM.REC.1398.196).

\section{Study procedure}

The researcher reviewed a list of daily outpatient clinic appointments in terms of inclusion criteria. If a patient met the inclusion criteria, the child and her/his parents were informed of the study's objectives, and if they agreed to participate, their written and signed informed consents were obtained. Then, their demographic and clinical information was completed by an occupational therapist. This information includes age, gross motor function level using gross motor function classification system expanded and revised (GMFCS-E\&R) [13], manual ability level using manual ability function classification system (MACS) [14], mini-MACS [15]. Also, the subtype of CP was determined according to the quality and topographical pattern of motor impairment [16].

Dental examinations were conducted according to the World Health Organization (WHO) protocol, used flat dental mirrors, a special dental CPI-probe (WHOprobe), and sufficient light on the dental unit by a dentist.

The periodontal status of children with $\mathrm{CP}$ was evaluated using the community periodontal index (CPI) [17, 18]. Then, the teeth status was examined for caries according to the Decayed, Missing, Filled (DMF) index [19].

\section{Outcome Measurements}

The gross motor function classification system: expanded and revised (GMFCS-E\&R) assesses children up to 18 years of age [13]. It classifies gross motor function on a 5-point ordinal scale. The reliability of GMFCSE\&R had been established in Persian for children with
CP [20]. In 2006, the manual ability classification system (MACS) was designed to describe hand performance in activities of daily living for children with CP. Its validity and reliability had been established in Persian [21].

To achieve CPI, the surfaces of all erupted teeth were examined for gingival bleeding and gingival pocket and scored as follows: (0) health periodontal conditions; (1) gingival bleeding on probing; (2) calculus and bleeding; (3) periodontal pocket depth of 4-5 $\mathrm{mm}$; and (4) periodontal pocket $\geq 6 \mathrm{~mm}[17,18]$. DMF index that was applied to the permanent and milk teeth using a CPI (WHO) probe, which considers fillings $(\mathrm{F})$ and decayed (D) and missing (M) teeth in an individual [19].

\section{Statistical analysis}

Due to the number of samples in the present study, levels I, II, IV, and V of classification systems (GMFCSE\&R, MACS, Mini MACS) were combined. The Chisquare test was used to analyze the intergroup difference based on motor function, manual ability levels. All statistical analyses were done at a significance level $<0.05$, using SPSS v. 16.

\section{Results}

The sample of this study consisted of 123 children with CP. Table 1 presents the characteristics of the study population. As was illustrated, of the 123 participants, $75(61 \%)$ were girls, and 48 were boys. Their Mean \pm SD age was 9.56 (4.38) years. The highest frequency in periodontal disease was in CPI code 2: calculus and bleeding and the lowest in code 4 : periodontal pocket $\geq 6 \mathrm{~mm}$. In this study, 88 children $(71.54 \%$ ) with $\mathrm{CP}$ had at least one missing tooth and $97(78.86 \%)$ at least one tooth filling.

Results showed that periodontitis was significantly different among children of different ages $\left(\chi^{2}=31.165\right.$, $\mathrm{P}=0.001)$ and was more common among the $10-15$ years old group (45.6\%) than other age groups. Comparing the periodontitis of CP children with different levels of gross motor function showed that the differences were statistically significant $\left(\chi^{2}=6.268, \mathrm{P}=0.024\right)$ and more common among level IV and V GMFCS-E\&R (51.5\%) than other levels of GMFCS-E\&R. Periodontitis was also more common among children with $\mathrm{CP}$ in level IV and V MACS $(39.7 \%)\left(\chi^{2}=6.913, \mathrm{P}=0.032\right)$. At mini-MACS levels, children with $\mathrm{CP}$ did not have periodontitis and were all in health periodontal conditions code. Besides, there was a significant relationship between periodontitis and the type of $\mathrm{CP}\left(\chi^{2}=33.42, \mathrm{P}=0.001\right)$. The periodontitis in spastic quadriplegia $(36.8 \%)$ was higher than other 
Table 1. Clinical characteristics in children with $\mathrm{CP}(\mathrm{n}=123)$

\begin{tabular}{|c|c|c|}
\hline \multicolumn{2}{|c|}{ Clinical Characteristics } & \multirow{2}{*}{$\begin{array}{l}\text { No.(\%) } \\
23(18.7)\end{array}$} \\
\hline \multirow{4}{*}{ Age groups (y) } & $<5$ & \\
\hline & $5-10$ & $43(35)$ \\
\hline & $10-15$ & $44(35.8)$ \\
\hline & $>15$ & 13(10.6) \\
\hline \multirow{7}{*}{ Type of CP } & Spastic hemiplegia & $37(30.1)$ \\
\hline & Spastic diplegia & $24(19.5)$ \\
\hline & Spastic quadriplegia & $29(23.6)$ \\
\hline & Ataxic & $9(7.3)$ \\
\hline & Dyskinetic & $11(8.9)$ \\
\hline & Chorea athetosis & $10(8.1)$ \\
\hline & Hypotonic & $3(2.4)$ \\
\hline \multirow{3}{*}{ GMFCS-E\&R } & I, II & $52(42.3)$ \\
\hline & III & $16(13)$ \\
\hline & IV, V & $55(44.7)$ \\
\hline \multirow{3}{*}{ MACS } & I, II & $37(35.2)$ \\
\hline & III & $33(21.4)$ \\
\hline & IV, V & $35(33.3)$ \\
\hline \multirow{3}{*}{ Mini-MACS } & I, II & $5(27.8)$ \\
\hline & III & $3(16.7)$ \\
\hline & $\mathrm{IV}, \mathrm{V}$ & $10(55.6)$ \\
\hline
\end{tabular}

\begin{tabular}{|ccc}
\hline & Periodontal disease codes & \\
\hline CPI & No.(\%) \\
\hline 0- Health periodontal conditions & $55(44.7)$ \\
\hline 1- Gingival bleeding on probing & $1(0.8)$ \\
\hline 2- Calculus and bleeding & & $64(52)$ \\
\hline 3- Periodontal pocket depth of 4-5mm & & $2(1.6)$ \\
\hline 4- Periodontal pocket $\geq 6 \mathrm{~mm}$ & & $1(0.8)$ \\
\hline DMFT index & 0 & $\mathrm{n}(\%)$ \\
\hline Filling & $\geq 1$ & $26(21.1)$ \\
\hline Decay & 0 & $97(78.9)$ \\
\hline & $\geq 1$ & $23(18.7)$ \\
\hline Missing & 0 & $100(81.3)$ \\
& $\geq 1$ & $35(28.5)$ \\
\hline
\end{tabular}

CP: Cerebral Palsy; CPI: Community Periodontal Index; GMFCS-E\&R: Gross Motor Function Classification System: Expanded and Revised; MACS: Manual Ability Function Classification System; DMFT: Decayed, Missing, Filled Teeth. 
Table 2. CPI among children according to age groups, GMFCS-E\&R, MACS, subtype of CP

\begin{tabular}{|c|c|c|c|c|c|c|}
\hline \multirow{2}{*}{\multicolumn{2}{|c|}{ Variables }} & \multicolumn{2}{|c|}{$\begin{array}{c}\text { No.(\%) } \\
\text { Periodontitis }\end{array}$} & \multirow{2}{*}{$x^{2}$} & \multirow[t]{2}{*}{ df } & \multirow[t]{2}{*}{$\mathbf{P}$} \\
\hline & & Healthy & Unhealthy & & & \\
\hline \multirow{5}{*}{ Age groups (y) } & $<5$ & $22(40)$ & $1(1.5)$ & \multirow{5}{*}{31.165} & \multirow{5}{*}{3} & \multirow{5}{*}{0.0001} \\
\hline & $5-10$ & $17(30.9)$ & $26(38.2)$ & & & \\
\hline & & & & & & \\
\hline & $10-15$ & 13(23.6) & $31(45.6)$ & & & \\
\hline & $>15$ & $3(5.5)$ & $10(14.7)$ & & & \\
\hline \multirow{3}{*}{ GMFCS-E\&R } & I, II & $30(54.5)$ & $22(32.4)$ & \multirow{3}{*}{6.268} & \multirow{3}{*}{2} & \multirow{3}{*}{0.044} \\
\hline & III & $5(9.1)$ & $11(16.2)$ & & & \\
\hline & $\mathrm{IV}, \mathrm{V}$ & $20(36.4)$ & $35(51.5)$ & & & \\
\hline \multirow{3}{*}{ MACS } & I, II & $19(34.5)$ & $18(26.5)$ & \multirow{3}{*}{6.913} & \multirow{3}{*}{2} & \multirow{3}{*}{0.032} \\
\hline & III & $10(18.2)$ & $23(33.8)$ & & & \\
\hline & IV, V & $8(14.5)$ & $27(39.7)$ & & & \\
\hline \multirow{5}{*}{ Type of CP } & Spastic & $43(78.3)$ & $47(69.1)$ & \multirow{5}{*}{33.42} & \multirow{5}{*}{6} & \multirow{5}{*}{0.001} \\
\hline & Ataxic & $3(5.5)$ & $6(8.8)$ & & & \\
\hline & Dyskinetic & $8(14.5)$ & $3(4.4)$ & & & \\
\hline & Chorea & 0 & $10(14.7)$ & & & \\
\hline & Hypotonic & $1(1.8)$ & $2(2.9)$ & & & \\
\hline
\end{tabular}

Iranian Rehabilitation Journa

CP: Cerebral Palsy; GMFCS-E\&R: Gross Motor Function Classification System: Expanded and Revised; MACS: Manual Ability Function Classification System.

types of CP (Table 2). No statistically significant differences were found between the DMF index of CP children in terms of different age groups, gross motor level, manual ability level, and subtype of CP (Table 3).

\section{Discussion}

This study was conducted to identify associations between gross motor function, manual ability levels, and subtypes of $\mathrm{CP}$ and periodontal and dental diseases in children with CP. In the present study, 68 children (55.3\%) with CP suffered from periodontitis. The results in this study were similar to those reported elsewhere [6, 22-24]. Another study examined plaque status and gingival health in 140 children with CP in Riyadh, with mild to moderate plaque accumulation and gingivitis increased as the age of the children increase [22]. Guare and Ciampioni reported that periodontal diseases such as gingivitis and plaque were more common in children with CP than in healthy children [24].
Among the main findings, a significant relationship was found between periodontal disease and subtype of CP. Periodontal disease was more prevalent in children with spastic quadriplegia. The results of this study were consistent with Jan's study that showed gingival hyperplasia and bleeding occur more frequently in children with $\mathrm{CP}$, and periodontal disease occurs in spastic quadriplegia children, especially in older ages [8]. A possible explanation for this result may be that children with severe $\mathrm{CP}$ have difficulty in access to dental services and have great challenges for oral hygiene [25], particularly if the children with severe $\mathrm{CP}$ have pathological primitive oral reflexes such as gagging, biting, rooting, and suckle-swallow reflexes [9].

The periodontal disease appeared to be significantly higher in gross motor function level, and periodontal diseases were higher in levels IV and V of GMFCS in children with CP. Sedky reviewed the oral health status of Egyptian children with $\mathrm{CP}$ in terms of gross motor levels 
Table 3. DMF index among children according to age groups, GMFCS-E\&R, MACS, subtype of CP

\begin{tabular}{|c|c|c|c|c|}
\hline \multicolumn{2}{|c|}{ Variables } & \multirow{2}{*}{$\frac{\chi^{2}}{1.640}$} & \multirow{2}{*}{$\begin{array}{l}\text { df } \\
3\end{array}$} & \multirow{2}{*}{$\begin{array}{c}\mathbf{P} \\
0.650\end{array}$} \\
\hline Missing & & & & \\
\hline Filling & Age groups & 3.254 & 3 & 0.354 \\
\hline Decayed & & 1.145 & 3 & 0.766 \\
\hline Missing & & 1.544 & 2 & 0.462 \\
\hline Filling & GMFCS: E\&R & 0.922 & 2 & 0.631 \\
\hline Decayed & & 5.535 & 2 & 0.063 \\
\hline Missing & & 2.486 & 2 & 0.289 \\
\hline Filling & MACS & 3.197 & 2 & 0.202 \\
\hline Decayed & & 4.361 & 2 & 0.113 \\
\hline Missing & & 3.793 & 6 & 0.705 \\
\hline Filling & Subtype of CP & 7.003 & 6 & 0.321 \\
\hline Decayed & & 0.890 & 6 & 0.989 \\
\hline
\end{tabular}

CP: Cerebral Palsy; GMFCS-E\&R: Gross Motor Function Classification System: Expanded and Revised; MACS: Manual Ability Function Classification System; DMF: Decayed, Missing, Filled.

and types of CP and reported that GMFCS is the best predictor variable for gingivitis and children in levels IV and V GMFCS compared to children in levels I, II, and III experience 17 times more severe gingivitis [26]. A possible explanation for this might be the severity of the neurological damage in children with $\mathrm{CP}$, which increases the risk of periodontitis [9, 24]. The children in levels IV and V of GMFCS have more plaque, food debris, and mouth breathing rate, explaining the higher rate of caries [9]. These children need to get efficient oral hygiene, but they have limited access to dental care services.

Furthermore, the periodontal disease appeared to be significantly higher in CP children aged $10-15$ years that was similar to that reported by Sedky et al. [26]. Age was as the second predictor variable that older children at levels IV and V had 6.6 times more likely than younger children at levels I, II, III to be more prone to gingivitis, and $57.7 \%$ of children with CP aged 7-10 years and older had more severe gingivitis [26].

In the present study, 88 children (71.54\%) with $\mathrm{CP}$ had at least one missing tooth, 97 (78.86\%) at least one filled tooth, and $100(81.30 \%)$ at least one decay tooth, which is in accord with the findings of earlier studies [27-29]. Dos Santos et al. reported that CP children with permanent dentitions have a more mean decayed, missing, and filled surfaces index, also as a more plaque index for both sexes than healthy children [28]. In a study in Brazil, $49.5 \%$ of children with CP had at least one tooth with untreated caries, and the prevalence of untreated dental caries was higher than the population of healthy children in the same age range [27]. No association was found between dental disease and subtype of $\mathrm{CP}$, gross motor function, and manual ability levels. It is a consensus in literature [30, 31]. Furthermore, this finding contradicts other studies [26, 32], which suggest that DMF score was influenced by GMFCS, MACS, and subtype of CP. One of the reasons for the lack of agreement may be the type of study. Quritum et al. [32] and Sedky et al. [26] studies were case-control studies with two groups of CP children and a control group, while Cardoso et al. [30] and our study were cross-sectional with only children with CP.

One of the limitations of this study was the convenience sampling method, and only children with CP of dentistry and rehabilitation centers supervised by TUMS were enrolled in the study.

\section{Conclusion}

The results showed that children with CP often suffered from periodontal disease, especially plaque and bleeding. These diseases were more prevalent in the IV and V GM- 
FCS-E\&R and age group of 10-15 years. Also, the prevalence of dental problems (missing, filled, the decayed tooth) was high at all levels of GMFCS-E\&R, different ages, and types of CP. As these children are at risk for dental caries and periodontal disease, earlier preventive strategies should be incorporated within therapeutic programs for children with CP. Furthermore, it is suggested that a dental care system be developed for these children with disabilities that help to improve the oral health education of parents, caregivers, and nurses, reinforcing childhood prevention programs, and motivating dentists. Also, oral-dental problems and their effect on nutrition in children with CP should be included in the curriculum for Occupational Therapy (OT) students in daily livings.

\section{Ethical Considerations}

\section{Compliance with ethical guidelines}

The Ethics Committee of Tehran University of Medical Sciences approved this study (Code: IR.TUMS.FNM. REC.1398.196).

\section{Funding}

This research was supported by Tehran University of Medical Sciences (Grant No.: 43162).

\section{Authors' contributions}

Conceptualization: Leila Dehghan, Hamid Dalvand, Hooshang Dadgar; Methodology: Hamid Dalvand, Leila Dehghan, Saman Maroufizadeh, Sarvin Sarmadi; Investigation: Leila Dehghan, Hamid Dalvand; Writing - original draft: Leila Dehghan, Hamid Dalvand ; Writing - review \& editing: All authors; Supervision: Leila Dehghan.

\section{Conflict of interest}

The authors declared no conflict of interest.

\section{Acknowledgments}

The authors are grateful to all mothers of children with $\mathrm{CP}$ that devoted their time and participated in this study.

\section{References}

[1] Khandaker G, Smithers-Sheedy H, Islam J, Alam M, Jung J Novak I, et al. Bangladesh Cerebral Palsy Register (BCPR): A pilot study to develop a national Cerebral Palsy $(\mathrm{CP})$ register with surveillance of children for CP. BMC Neurology. 2015 15(1):173. [DOI:10.1186/s12883-015-0427-9] [PMID] [PMCID]

[2] Polat Z, Akgun ÖM, Turan I, Polat GG, Altun C. Evaluation of the relationship between dental erosion and scintigraphically detected gastroesophageal reflux in patients with cerebral palsy. Turkish Journal of Medical Sciences. 2013; 43(2):283-8. https://dergipark.org.tr/tr/download/article-file/128325

[3] Maiya A, Shetty YR, Rai K, Padmanabhan V, Hegde AM Use of different oral hygiene strategies in children with cerebral palsy: A comparative study. Journal of International Society of Preventive \& Community Dentistry. 2015; 5(5):389-93. [DOI:10.4103/2231-0762.165925] [PMID] [PMCID]

[4] Sharma P, Golchha V, Tokas Y. Prevalence of dental caries in children with cerebral palsy in relation to body mass index trends. Indian Journal of Contemporary Dentistry. 2014; 2(1):110-4. [DOI:10.5958/j.2320-5962.2.1.022]

[5] Subasi F, Mumcu G, Koksal L, Cimilli H, Bitlis D. Factors affecting oral health habits among children with cerebral palsy: Pilot study. Pediatrics International. 2007; 49(6):853-7. [DOI:10.1111/j.1442-200X.2007.02445.x] [PMID]

[6] Santos MTBR, Ferreira MCD, Guaré RO, Diniz MB, Rösing $\mathrm{CK}$, Rodrigues JA, et al. Gingivitis and salivary osmolality in children with cerebral palsy. International Journal of Paediatric Dentistry. 2016; 26(6):463-70. [DOI:10.1111/ipd.12220] [PMID]

[7] Jan MM. Clinical review of pediatric epilepsy. Neurosciences. 2005; 10(4):255-64. [PMID]

[8] Jan BM, Jan MM. Dental health of children with cerebral palsy. Neurosciences. 2016; 21(4):314-8. [DOI:10.17712/ nsj.2016.4.20150729] [PMID] [PMCID]

[9] Dos Santos M, Nogueira M. Infantile reflexes and their effects on dental caries and oral hygiene in cerebral palsy individuals. Journal of Oral Rehabilitation. 2005; 32(12):880-5. [DOI:10.1111/j.1365-2842.2005.01518.x] [PMID]

[10] Chandra Pani S, Fahad AlEidan S, Nasser AlMutairi R, Ali AlAbsi A, Nasser AlMuhaidib D, Faisal AlSulaiman H, et al. The impact of gross motor function on the oral health-related quality of life in young adults with cerebral palsy in Saudi Arabia. International Journal of Dentistry. 2020; 2020:4590509. [DOI:10.1155/2020/4590509] [PMID] [PMCID]

[11] Akhter R, Hassan NMM, Martin EF, Muhit M, Haque MR Smithers-Sheedy $\mathrm{H}$, et al. Risk factors for dental caries among children with cerebral palsy in a low-resource setting. Developmental Medicine \& Child Neurology. 2017; 59(5):538-43. [DOI:10.1111/dmcn.13359] [PMID]

[12] Kuperminc M, Gottrand F, Samson-Fang L, Arvedson J, Bell K, Craig G, et al. Nutritional management of children with cerebral palsy: A practical guide. European Journal of Clinical Nutrition. 2013; 67(2):S21-3. [DOI:10.1038/ ejcn.2013.227] [PMID]

[13] Palisano RJ, Rosenbaum P, Bartlett D, Livingston MH Content validity of the expanded and revised Gross Motor Function Classification System. Developmental Medicine and Child Neurology. 2008; 50(10):744-50. [DOI:10.1111/j.14698749.2008.03089.x.] [PMID] 
[14] Eliasson AC, Krumlinde-Sundholm L, Rösblad B, Beckung E, Arner M, Öhrvall AM, et al. The Manual Ability Classification System (MACS) for children with cerebral palsy: Scale development and evidence of validity and reliability. Developmental Medicine \& Child Neurology. 2006; 48(7):549-54. [DOI:10.1111/j.1469-8749.2006.tb01313.x] [PMID]

[15] Eliasson AC, Ullenhag A, Wahlström U, Krumlinde-Sundholm L. Mini-MACS: Development of the Manual Ability Classification System for children younger than 4 years of age with signs of cerebral palsy. Developmental Medicine \& Child Neurology. 2017; 59(1):72-8. [DOI:10.1111/dmcn.13162] [PMID]

[16] Shevell MI, Majnemer A, Poulin C, Law M. Stability of motor impairment in children with cerebral palsy. Developmental Medicine \& Child Neurology. 2008; 50(3):211-5. [DOI:10.1111/j.1469-8749.2008.02029.x] [PMID]

[17] Ainamo J, Barmes D, Beagrie G, Cutress T, Martin J, Sardo-Infirri J. Development of the World Health Organization (WHO) community periodontal index of treatment needs (CPITN). International Dental Journal. 1982; 32(3):281-91. [PMID]

[18] Cutress TW, Ainamo J, Sardo-Infirri J. The Community Periodontal Index of Treatment Needs (CPITN) procedure for population groups and individuals. International Dental Journal. 1987; 37(4):222-33. [PMID]

[19] World Health Organization (WHO). Oral health surveys: Basic methods [Internet]. 1997. Available from: https://apps. who.int/iris/handle/10665/41905

[20] Dehghan L, Abdolvahab M, Bagheri H, Dalvand H, Faghih zade S. [Inter rater reliability of Persian version of Gross Motor Function Classification System Expanded and Revised in patients with cerebral palsy (Persian)]. Daneshvar Medicine; Basic and Clinical Research Journal. 2011; 18(6):37-44. http:// daneshvarmed.shahed.ac.ir/article_1446.html?lang=en

[21] Riyahi A, Rassafiani M, AkbarFahimi N, Sahaf R, Yazdani F. Cross-cultural validation of the Persian version of the Manual Ability Classification System for children with cerebral palsy. International Journal of Therapy and Rehabilitation. 2013; 20(1):19-24. [DOI:10.12968/ijtr.2013.20.1.19]

[22] Alhammad NS, Wyne AH. Plaque and gingival health status among cerebral palsied children of riyadh city. Pakistan Oral \& Dental Journal. 2011;31 (1):118-21. https://pesquisa. bvsalud.org/portal/resource/pt/emr-124708

[23] Cardoso AMR, de Medeiros MMD, Gomes LN, Martins ML, Padilha WWN, Cavalcanti AL. Factors associated with health and oral health-related quality of life of children and adolescents with cerebral palsy. Special Care in Dentistry. 2018; 38(4):216-26. [DOI:10.1111/scd.12301] [PMID]

[24] Guare Rde O, Ciampioni AL. Prevalence of periodontal disease in the primary dentition of children with cerebral palsy. Journal of Dentistry for Children. 2004; 71(1):27-32. [PMID]

[25] Silva ELMSd, Góes PSAd, Vasconcelos MMVB, Jamelli SR, Eickmann SH, Melo MMDCd, et al. Oral health care for children and adolescents with cerebral palsy: Perceptions of parents and caregivers. Ciência \& Saúde Coletiva. 2020; 25(10):3773-84. [DOI:10.1590/1413-812320202510.27972018] [PMID]

[26] Sedky NA. Assessment of oral and dental health status in children with cerebral palsy: An exploratory study. International Journal of Health Sciences. 2018; 12 (1):4-14. [DOI:10.5005/jp-journals-10031-1177]
[27] DE Camargo MAF, Antunes JLF. Untreated dental caries in children with cerebral palsy in the Brazilian context. International Journal of Paediatric Dentistry. 2008; 18 (2):131-8. [DOI:10.1111/j.1365-263X.2007.00829.x] [PMID]

[28] Dos Santos MTBR, Masiero D, Simionato MRL. Risk factors for dental caries in children with cerebral palsy. Special Care in Dentistry. 2002; 22 (3):103-7. [DOI:10.1111/j.1754-4505.2002. tb01171.x] [PMID]

[29] Eskandari M, Khosoosi Sani A. [Survey of developmental defect of enamel incidence in 11-13 years old students in Rasht (Persian)]. Journal of Guilan University of Medical Sciences. 2008; 16(64):32-6. http://journal.gums.ac.ir/article-1-341-en.html

[30] Cardoso AMR, Silva CRD, Gomes LN, Gomes MdNC, Padilha WWN, Cavalcanti AL. Dental trauma in Brazilian children and adolescents with cerebral palsy. Dental Traumatology. 2015; 31(6):471-6. [DOI:10.1111/edt.12184] [PMID]

[31] de Carvalho RB, Mendes RF, Prado Jr RR, Neto JMM. Oral health and oral motor function in children with cerebral palsy. Special Care in Dentistry. 2011; 31(2):58-62. [DOI:10.1111/ j.1754-4505.2011.00180.x] [PMID]

[32] Quritum SM, Dowidar K, Ahmed AM, Omar TE. Impact of oral health behaviours on dental caries in children with cerebral palsy: A case-control study. Alexandria Dental Journal. 2019; 44(1):1-6. [DOI:10.21608/adjalexu.2019.57565] 